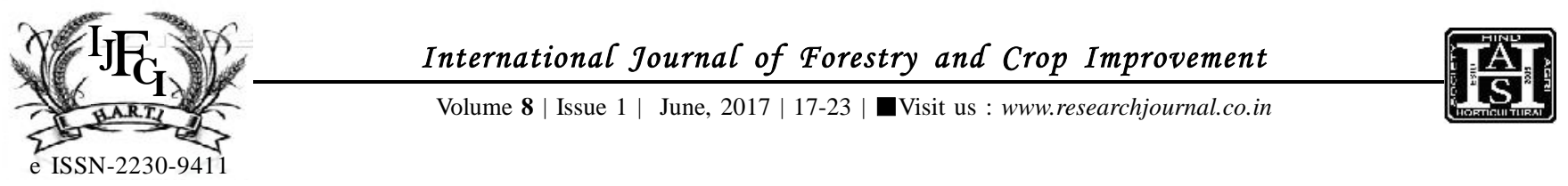

\title{
Identification of mechanization gaps for different farm operations for fodder and crop cultivation in Pusa (Bihar) region
}

\author{
DHEERAJ KUMAR AND MANORANJAN KUMAR
}

\begin{abstract}
The present study deals the status of mechanization gaps for different farm operations for sustainable farming in Pusa region. Cattle farms based on grassland are dynamic system and it's difficult to manage, mainly because of their compassion to uncontrollable environmental factors. There are so many challenging issues regarding management strategies for efficient use of inputs. To meet the growing demand of population and productivity of land, agriculture mechanization is one of the important promising approaches. The outcome obtained from the survey conducted in a cattle farm of Dr. Rajendra Prasad Central Agricultural University, Pusa (Samastipur) Bihar shows approx $0.87 \mathrm{hp} / \mathrm{ha}$ utilization of farm power in terms of available machinery for farm operations which was established less than reported a value of power utilization e.g. $1.5 \mathrm{hp} / \mathrm{ha}$ for successful farm operation through mechanization. Moreover, seeds loss can be reduced during sowing operation by using specific machine. Mechanization also facilitates interculturing activities and sowing operation too which intern produces a good quality fodder. Nutritious fodder is required to enhance the quality of milk. Mechanization is an essential step to maintain the health of cattle and its produce.
\end{abstract}

KEY WORDS : Farm mechanization, Status of farm, Milk quality, Mechanization gape

HOW TO CITE THIS ARTICLE : Kumar, Dheeraj and Kumar, Manoranjan (2017). Identification of mechanization gaps for different farm operations for fodder and crop cultivation in Pusa (Bihar) region. Internat. J. Forestry \& Crop Improv., 8 (1) : 17-23, DOI: 10.15740/HAS/ IJFCI/8.1/17-23.

Article Chronical : Received : 21.01.2017; Revised : 27.04.2017; Accepted : 07.05.2017 